\title{
Appropriateness of colonoscopy in Europe (EPAGE II) Screening for colorectal cancer
}

Authors

Institutions
C. Arditi' ${ }^{1}$ I. Peytremann-Bridevaux', B. Burnand ${ }^{1}$, V. F. Eckardt² ${ }^{2}$ P. Bytzer ${ }^{3}$, L. Agréus ${ }^{4}$, R. W. Dubois ${ }^{5}$, J.-P. Vader ${ }^{1}$, F. Froehlich ${ }^{6,7}$, V. Pittet ${ }^{1}$, S. Schusselé Filliettaz ${ }^{1}$, P. Juillerat ${ }^{6}$, J.-J. Gonvers ${ }^{6}$ and the EPAGE II Study Group ${ }^{8}$

Institutions are listed at the end of article. submitted 17 June 2008 accepted after revision 5 December 2008

\section{Bibliography}

DOI 10.1055/s-0028-1119626

Endoscopy 2009; 41:

200-208 @ Georg Thieme Verlag KG Stuttgart · New York ISSN 0013-726X

\section{Corresponding author} J.-J. Gonvers, MD

Policlinique Médicale Universitaire (PMU/CHUV)

Rue du Bugnon 44

CH-1011 Lausanne Switzerland

Fax: +41-21-3144718 jean-jacques.gonvers@chuv.ch
Background and study aims: To summarize the published literature on assessment of appropriateness of colonoscopy for screening for colorectal cancer (CRC) in asymptomatic individuals without personal history of CRC or polyps, and report appropriateness criteria developed by an expert panel, the 2008 European Panel on the Appropriateness of Gastrointestinal Endoscopy, EPAGE II.

Methods: A systematic search of guidelines, systematic reviews, and primary studies regarding colonoscopy for screening for colorectal cancer was performed. The RAND/UCLA Appropriateness Method was applied to develop appropriateness criteria for colonoscopy in these circumstances. Results: Available evidence for CRC screening comes from small case-controlled studies, with heterogeneous results, and from indirect evidence from randomized controlled trials (RCTs) on fecal occult blood test (FOBT) screening and studies on flexible sigmoidoscopy screening. Most guidelines recommend screening colonos-

\section{Introduction}

$\nabla$

Cancer of the colon and rectum (colorectal cancer [CRC]) is one of the most common cancers diagnosed in Western countries and is a major cause of cancer-associated morbidity and mortality $[1,2]$. In Europe, the annual age-standardized incidence of CRC is 35 and 55 per 100000 in women and in men respectively [1]. The age distribution of CRC shows a predominance in patients $>50$ years with less than $10 \%$ of patients being younger than 50 years [3]. The mean age at diagnosis was found to range from 65 to 71.5 years [4]. CRC is the second major cause of cancer mortality in both women and men. While the survival rate for early-stage cancers is high, the survival rate for those diagnosed with widespread cancer is low. About $75 \%$ of all new cases of CRC occur in asymptomatic individuals with no known predisposing factor for the disease except age ( $\geq 50$ years old; copy every 10 years starting at age 50 in averagerisk individuals. In individuals with a higher risk of CRC due to family history, there is a consensus that it is appropriate to offer screening colonoscopy at $<50$ years. EPAGE II considered screening colonoscopy appropriate above 50 years in averagerisk individuals. Panelists deemed screening colonoscopy appropriate for younger patients, with shorter surveillance intervals, where family or personal risk of colorectal cancer is higher. A positive FOBT or the discovery of adenomas at sigmoidoscopy are considered appropriate indications.

Conclusions: Despite the lack of evidence based on randomized controlled trials (RCTs), colonoscopy is recommended by most published guidelines and EPAGE II criteria available online (http://www.epage.ch), as a screening option for CRC in individuals at average risk of CRC, and undisputedly as the main screening tool for CRC in individuals at moderate and high risk of CRC.

average risk) [5]. The remaining cases occur in individuals with a family history of CRC or adenomatous polyps, or with a family history of hereditary nonpolyposis colorectal cancer (HNPCC), or with familial adenomatous polyposis (FAP) or attenuated FAP. Screening, which refers to the search for colorectal lesions in asymptomatic patients with no personal history of CRC or adenomas, appears to be the best option available to reduce CRC morbidity and mortality by early detection of CRC in individuals $\geq 50$ years old. However, there is debate about the best screening method and about whether colonoscopy should be recommended for CRC screening.

In April 2008, a multidisciplinary European expert panel was convened in Montreux, Switzerland, to discuss and develop criteria for the appropriate use of colonoscopy. This article presents the literature review on screening for CRC in asymptomatic individuals that was provided to 
the panelists before the panel meeting to support their ratings of appropriateness of use of colonoscopy for such screening, and also presents the panel's results. It updates the previous literature review and consideration of appropriateness criteria that was published in 1999 [6].

The aim of this review is to assess the effectiveness/appropriateness of colonoscopy for screening for CRC in asymptomatic individuals, at average risk ( $\geq 50$ years old), at slight or moderate risk (with a family history of CRC or adenomatous polyps) and at high risk (with a family history of HNPCC, FAP, or attenuated FAP). The use of colonoscopy for surveillance after polypectomy and after resection of CRC is reviewed in a companion article in this issue.

\section{Method}

$\nabla$

The literature review process included a systematic search of websites issuing guidelines and of Medline (1997-February 2008) to select published guidelines, systematic reviews, and primary studies assessing the use of colonoscopy for CRC screening. With the exception of certain relevant articles, the literature published before 1997 is presented in the previous literature review [6].

The application of the RAND/UCLA Appropriateness Method is described in detail in a companion article in this issue [7]. Briefly, the RAND process is a formal explicit expert panel method that allows classification of each indication into one of the following categories of appropriateness: inappropriate, uncertain, appropriate, and appropriate and necessary (that is, mandating colonoscopy). To simplify the graphical presentation of the appropriateness results, these four categories were consolidated into two clusters: "Appropriate" (comprising the categories appropriate, and appropriate and necessary) and "Not appropriate" (comprising the categories inappropriate and uncertain). In addition to simplification and enhanced clarity of presentation, the rationale for this choice was that in many instances in the case of a nonappropriate scenario, whether it be uncertain or inappropriate, the decision for not proposing the colonoscopy should be specifically discussed and shared with the patient. All clinical indications and their ratings are available on the EPAGE website (www.epage.ch).

\section{Results: Literature review \\ $\nabla$}

Primary studies on the use of colonoscopy for CRC screening in asymptomatic individuals at average risk Colonoscopy is usually considered to be the gold standard examination for adenoma and CRC detection. Single-test sensitivity was reported to be $90 \%$ for large adenomas and $75 \%$ for small adenomas $(<1 \mathrm{~cm})$; sensitivity for cancer was $>90 \%$ [8]. However, insufficient procedural competence and experience on the part of the endoscopist may impair test performance [9] and recent studies comparing computed tomography colonography with colonoscopy have found greater miss rates for colonoscopy than previously described $[10,11]$.

The diagnostic yield of CRC screening by colonoscopy in studies published since 1997 is presented in Table e1 [12 - 23]. In individuals aged $\geq 50$ years, rates range from $9 \%$ to $16 \%$ for adenomas, from $3 \%$ to $6 \%$ for advanced adenomas, and from $0 \%$ to $2.6 \%$ for cancer. In individuals aged 40-49, the diagnostic yield is lower (6\%-9\% for adenomas, $1 \%-3 \%$ for advanced adenomas, $<1 \%$ for cancer), while it is higher for individuals aged $>65$ years $(14 \%-$
$43 \%$ for adenomas, $12 \%-13 \%$ for advanced adenomas, $1 \%-3 \%$ for cancer). Rates are also lower in women compared with men $[13,14,17,19,23]$.

No randomized controlled study has evaluated whether screening colonoscopy alone reduces the incidence or mortality from CRC in people at average risk of the disease. There is currently one ongoing randomized controlled trial (RCT) investigating screening colonoscopy versus standard care (study I) and versus annual fecal occult blood test (FOBT) (study II) in patients aged 50 to 69 , conducted by Sidney Winawer in the US. Two case-controlled studies and one cohort study on colonoscopy screening for CRC have been published since 1997 [24-26], in addition to the two case-controlled studies published in 1995[27,28] (Table e2). In the latter studies $[27,28]$, men diagnosed with CRC were significantly less likely to have had colonoscopy before CRC diagnosis. The two recent case-controlled studies also showed that men and women diagnosed with CRC were less likely to have ever had colonoscopy before CRC diagnosis, but this result was not statistically significant in one study [25] and the results of the other study [24] are of limited use, as the specific impact of colonoscopy could not be separated from that of flexible sigmoidoscopy. In the cohort study, a negative screening colonoscopy was significantly associated with a reduced incidence of CRC over at least 10 years [26].

There is also indirect evidence from FOBT trials that FOBT followed by colonoscopy if the test is positive reduces CRC mortality[29-31]. Some authors have also suggested that evidence from flexible sigmoidoscopy studies, for which case-controlled studies showed a reduction in CRC mortality, can be extrapolated to colonoscopy as it provides a more complete examination of the colon [32]. In addition, recent evidence on the prevalence of advanced proximal neoplasia occurring in the absence of polyps in the distal colon $[17,33,34]$ also favors the use of colonoscopy rather than sigmoidoscopy as the primary method of CRC screening. Finally, colonoscopy with polypectomy has been shown in several studies [35-39] to significantly reduce the incidence of CRC and mortality from CRC.

The projected impact of screening colonoscopy on CRC incidence and mortality has also been estimated in cost-effectiveness studies, using various transition models in hypothetical average-risk individuals aged 50 years. In the model of Frazier et al. [40], screening colonoscopy every 10 years was estimated to reduce CRC incidence by $58 \%$ and CRC mortality by $64 \%$. In Sonnenberg \& Delcò's model [41], a single colonoscopy at age 65 was estimated to prevent $23 \%$ of CRCs, while colonoscopy every 10 years starting at age 50 was estimated to prevent $75 \%$ of CRCs. In the model of Vijan et al. [42], the estimated reduction in CRC mortality varied from a high $64 \%$ with the assumption of $100 \%$ patient compliance to a low $21 \%$ with $25 \%$ patient compliance.

\section{Guidelines on the use of colonoscopy for CRC screening} in asymptomatic individuals at average risk

Since 1997, many guidelines have been published on CRC screening. Guidelines on CRC screening in average-risk individuals, published since 2000 and that are of moderate and good quality [32,43-52], are reported in Table e3. While these guidelines agree that CRC screening is effective in reducing CRC mortality in average-risk individuals, there is no consensus on the best screening strategy. Indeed, while some guidelines recommend screening colonoscopy every 10 years starting at age 50 in average-risk individuals, others argue that they cannot recommend for or against colonoscopy due to the lack of evidence. 
The recommendation to begin CRC screening in average-risk patients at age 50 is supported by several studies confirming that CRC is infrequent in individuals aged $40-49$ years $[14,16,19]$. The 10-year interval for screening colonoscopy is based on evidence that it takes an average of 10 years for the transformation of an adenomatous polyp into an invasive cancer, and is supported by results from case-controlled and cohort studies showing very low rates of advanced neoplasia or cancer at 5-year followup $[26,53,54]$.

\section{Primary studies on the use of other tests for CRC} screening in asymptomatic individuals at average risk Published evidence on the effectiveness of FOBT and flexible sigmoidoscopy is briefly reviewed, due to the lack of consensus in guidelines on the appropriateness of colonoscopy and to the absence of randomized controlled trials on its effectiveness. In addition, a short overview of newer techniques, i.e. virtual colonoscopy and fecal DNA testing, is provided.

FOBT is a widely used noninvasive screening test for CRC, followed by colonoscopy in the event of a positive result. Its sensitivity for CRC detection is lower than that of colonoscopy, ranging from $37 \%$ to $80 \%$ [55-57], meaning that many cases of CRC are not detected by the initial FOBT screening. Authors therefore suggest repeating the test every year (annual) or every 2 years (biennial) if the test is negative. In contrast to screening colonoscopy, evidence on the effectiveness of screening FOBT comes from four large RCTs, with long follow-up periods (12-18 years) [2931,58-64] (Table e4). In the systematic review published by the Cochrane Collaboration in 2007 [65], results including the four abovementioned trials showed a statistically significant $16 \%$ reduction in CRC mortality with FOBT screening. No difference was found, however, in all-cause mortality. Some authors have argued that lesions found through screening programs with FOBT were likely to have been detected because of the high prevalence of colorectal lesions and the frequency of colonoscopy rather than because of the ability of FOBT to detect colorectal lesions [66,67]. Nevertheless, all guidelines include FOBT as a screening option for CRC.

Flexible sigmoidoscopy, usually followed by colonoscopy if an adenoma is found in the distal colon, was reported as identifying $70 \%$ to $80 \%$ of patients with advanced neoplasia[23, 68,69$]$. However, recent studies have demonstrated that a significant number of advanced proximal neoplasms occur in the absence of distal neoplasia in average-risk patients $[17,33,34]$, especially in women $[20]$ and older patients $[33,70]$. There is also a lack of consensus about which flexible sigmoidoscopy findings necessitate subsequent colonoscopy. Some authors advocate performing colonoscopy when any polyp is detected, while others recommend colonoscopy only after detection of large, multiple, or high-risk adenomas. The effectiveness of flexible sigmoidoscopy screening with colonoscopic follow-up was evaluated in a small RCT $[23,71,72]$, which showed a significantly lower incidence of CRC in individuals undergoing flexible sigmoidoscopy screening. Mortality results from six ongoing trials involving flexible sigmoidoscopy screening should soon be available [73-80]. Three case-controlled studies have been published since 1997 $[25,81,82]$ (Table e5) showing that sigmoidoscopy screening reduces mortality from cancer of the distal colon and rectum (odds ratio [OR] range $0.24-0.56$ ). However, in a case-controlled study published in 1995, sigmoidoscopy alone did not reduce mortality from CRC [27].
Computed tomography colonography (CTC), also called virtual colonoscopy, is a recent technique consisting of CT-scan images of the colon, which are then reconstructed by computer into virtual fly-through pictures of the colonic lumen. CTC is not yet endorsed by most guidelines as a screening option. In a meta-analysis of the accuracy of CTC [83], results showed that sensitivity was very heterogeneous (between $21 \%$ and $96 \%$ ). Improvements in technology, training, and standardization of the technique are required before CTC can be recommended for widespread screening [54].

Fecal DNA testing, which detects genetic mutations characteristic of CRC in cells found in stools, is also still under development. Its sensitivity was reported to be four times that of FOBT for detecting invasive cancer [84]. It has only recently been recommended for CRC screening by the US Multi-Society Task Force on CRC [52].

Primary studies on the use of colonoscopy for CRC screening in individuals with a family history of CRC or adenomatous polyps

Individuals with a family history of CRC or adenomatous polyps, but without any currently known genetic susceptibility (HNPCC or FAP), have an increased risk of developing CRC compared with those without a family history. In a meta-analysis of cohort and case-controlled studies, the pooled relative risk of developing CRC if at least one first-degree relative had been diagnosed with CRC was estimated at 2.24 (95\% CI 2.06-2.43), and increased to 3.97 (95\%CI 2.60-6.06) if at least two first-degree relatives were affected [85]. The pooled relative risk of CRC also increased to 3.87 (95\%CI 2.40-6.22) with a relative diagnosed with CRC before age 45 and was found to be 1.99 (95\%CI 1.55-2.55) with a first-degree relative with adenomatous polyps [86]. Yield of screening colonoscopy in persons with a positive family history of CRC or adenomas is indeed higher than in persons without a family history[87-90]. However, in individuals aged $<50$ years, the yield appears to be quite low, and some authors question the need for screening colonoscopy before the age of 50 years $[89,91]$.

No randomized study was found examining the effectiveness of screening colonoscopy in patients with a family history of CRC or adenoma, with regard to reducing CRC incidence and mortality. In a small case-controlled study of asymptomatic individuals participating in a screening colonoscopy program for first-degree relatives of CRC patients [92], screening colonoscopy had been performed previously in $2.5 \%$ of individuals diagnosed with CRC, compared with $48.7 \%$ of individuals without CRC $(P<.0001)$.

Guidelines on the use of colonoscopy for CRC screening in individuals with a family history of CRC or adenomatous polyps

Despite the absence of published studies on the effectiveness of screening colonoscopy in individuals with a family history of CRC or adenomas in reducing CRC incidence and mortality, published guidelines agree that it is appropriate to offer screening colonoscopy to individuals at slight or moderate risk of developing CRC on the basis of a positive family history $[32,43,45,46,48$, 49, 51,93, 94-96] (Table e6). They recommend starting screening at a lower age than for individuals at average risk. However, the definition of level of risk, the age at which to start screening colonoscopy, and the frequency of screening colonoscopy vary between guidelines. 
Table 92008 European Panel on the Appropriateness of Gastrointestinal Endoscopy (EPAGE II): definitions related to screening colonoscopy for colorectal cancer (CRC).

\begin{tabular}{|c|c|}
\hline Term & Definition \\
\hline Average risk & Any patient without slightly increased, moderately increased or high risk \\
\hline Slightly increased risk & $\begin{array}{l}\text { Any of the following: } \\
\text { Colorectal cancer in one first-degree relative } \\
\text { Colorectal cancer in two second-degree relatives } \\
\text { Adenomatous polyp in one first-degree relative } \\
\text { Personal history of ovarian or endometrial cancer } \\
\text { History of ovarian or endometrial cancer in one first-degree relative } \\
\text { First-degree relatives }\end{array}$ \\
\hline Moderately increased risk & $\begin{array}{l}\text { Any of the following: } \\
\text { Colorectal cancer in two first-degree relatives } \\
\text { Colorectal cancer in one first-degree relative with onset before age of } 50 \\
\text { First-degree relatives }\end{array}$ \\
\hline High risk & $\begin{array}{l}\text { Any of the following: } \\
\text { Family history of FAP } \\
\text { Family history of HNPCC } \\
\text { First-degree relatives }\end{array}$ \\
\hline Positive screening fecal occult blood test (FOBT) & At least one stool test for occult blood shows a positive reaction \\
\hline Sigmoidoscopy & Flexible tube $(60 \mathrm{~cm})$ \\
\hline Positive findings at screening sigmoidoscopy & $\begin{array}{l}\text { Low-risk adenoma } \\
\text { High-risk adenoma }\end{array}$ \\
\hline Low-risk adenomas & $\begin{array}{l}\text { All of the following: } \\
\text { No more than } 2 \text { adenomas } \\
\text { Size }<1 \mathrm{~cm} \\
\text { Tubular histology } \\
\text { No high-grade dysplasia } \\
\text { First-degree familial anamnesis negative }\end{array}$ \\
\hline High-risk adenomas & $\begin{array}{l}\text { Any of the following: } \\
\text { Villous or tubulovillous histology or serrated adenoma (any size, number or grade of dysplasia) } \\
\text { Size } \geq 1 \mathrm{~cm} \\
\text { Multiple adenomas }(\geq 3) \\
\text { Large sessile adenomas } \\
\text { High-grade dysplasia }\end{array}$ \\
\hline
\end{tabular}

HNPCC, hereditary nonpolyposis colorectal cancer; FAP, familial adenomatous polyposis

Primary studies and guidelines on the use of colonoscopy for CRC screening in individuals with a family history of hereditary nonpolyposis colorectal cancer (HNPCC) HNPCC is an autosomal-dominant inherited condition characterized by the development of CRC at a mean age of 45 years and a $80 \%$ lifetime risk of CRC $[97,98]$ and it is the most common hereditary form of CRC ( $5 \%-6 \%$ of all CRC cases). An accelerated adenoma-carcinoma progression is described owing to the presence of larger adenomas with more dysplasia than in nonfamilial cases [99]. Two-thirds of cancers occur in the right colon [99], thus necessitating an examination of the entire colon.

Only one prospective controlled study $[100,101]$ of screening colonoscopy for CRC in HNPCC families was found in the literature. Järvinen and colleagues found that a 3-year interval colonoscopy (or double-contrast barium enema and flexible sigmoidoscopy) screening in families with HNPCC significantly reduced the CRC rate of $62 \%$ within a 15 -year follow-up period [100].

Despite the lack of evidence, guidelines agree that it is appropriate to offer screening colonoscopy to individuals with a family history of HNPCC [32,43,46-49,51,93-96,98] (Table e7). They recommend colonoscopy starting at the age of $20-25$ years or 10 years prior to the earliest age at diagnosis in the family. The recommended interval for colonoscopy is every 1 or 2 years until age 40 , then annually.
Primary studies and guidelines on the use of colonoscopy for CRC screening in individuals with a family history of familial adenomatous polyposis (FAP)

FAP is an autosomal-dominant syndrome caused by mutations in the adenomatous polyposis coli (APC) gene, characterized by the presence of more than 100 adenomas in the colon. The average age for first adenomas in FAP is 16 years, and the average age for colon cancer is 39 years. Affected persons have a $100 \%$ risk of developing colorectal cancer [5]. A variant of FAP, called attenuated APC (AAPC), is associated with a variable number of adenomas (usually 20-100), a proximal colonic distribution of adenomas, and a relatively delayed onset of CRC that is approximately 10 years later than for FAP.

No controlled study was found on screening colonoscopy for CRC in patients with a family history of FAP or attenuated FAP. Most of the available evidence stems from observational studies in registries. In a study of patients in a registry, CRC mortality was significantly lower in patients who underwent endoscopy screening compared with those who presented with symptoms [102].

Current guidelines on endoscopic procedures for individuals with a family history of FAP are presented in Table e8 [32, $43,46-48,51,93-96]$. If the genetic test result is positive, annual flexible sigmoidoscopy is recommended, starting at the age of $10-15$ years. According to one guideline[46], colonoscopy is an alternative to flexible sigmoidoscopy and the Scottish guidelines [96] recommend colonoscopy every $2-3$ years in addition to flexible sigmoidoscopy. If the genetic test result is negative, most 


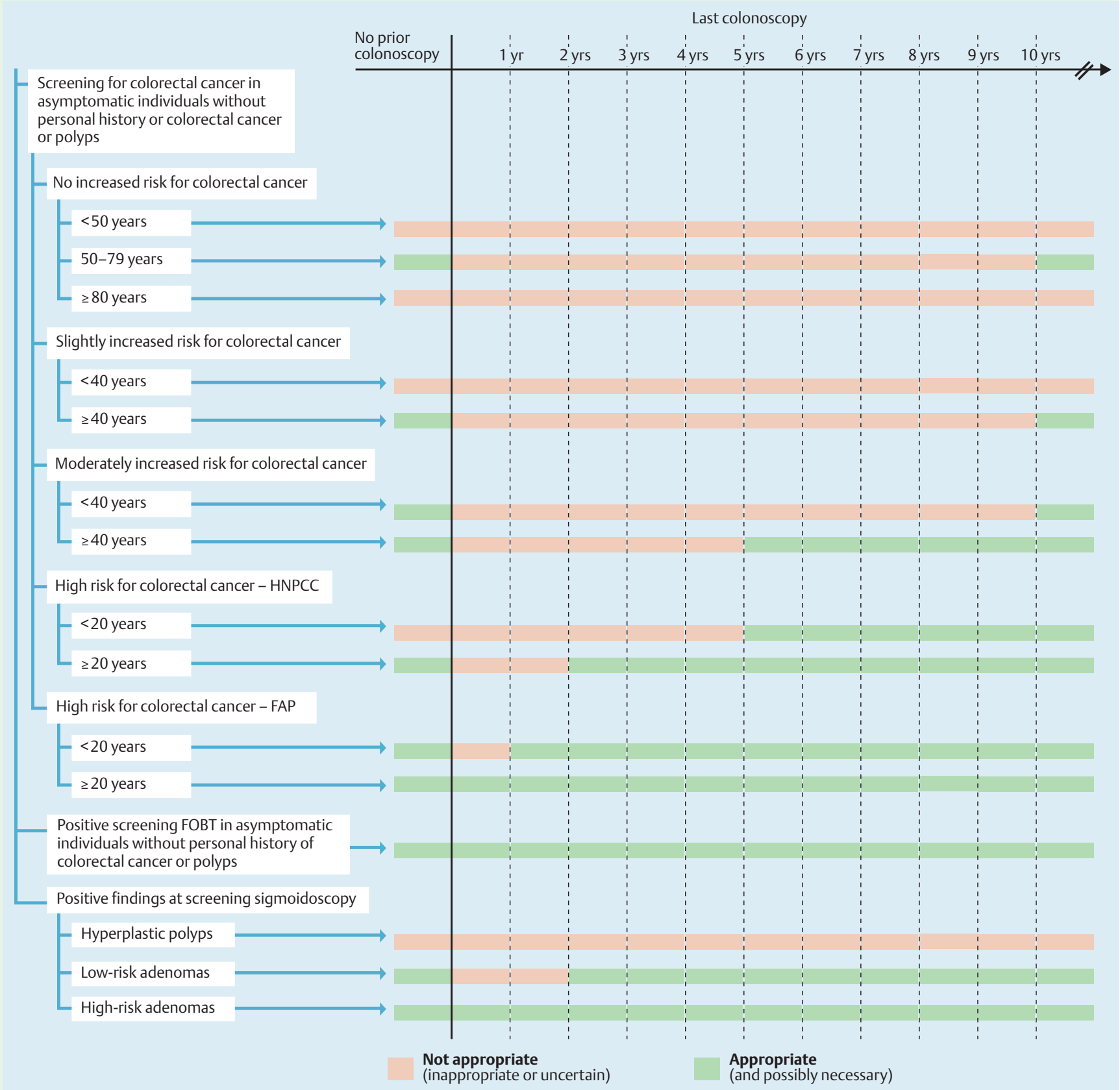

Fig. 1a Appropriateness of ratings of clinical indications for performing colonoscopy in patients for colorectal cancer (CRC) screening (simplified decision tree). HNPCC, hereditary nonpolyposis colorectal cancer; FAP, familial adenomatous polyposis; FOBT, fecal occult blood test. Copyright $\odot 2008$ IUMSP/CHUV, Lausanne, Switzerland - EPAGE II.

guidelines suggest screening as for average-risk individuals. In cases of attenuated FAP, guidelines recommend colonoscopy every 2-3 years, beginning in the late teens, because of the preponderance of proximal colonic adenomas.

\section{Results: EPAGE II appropriateness criteria}

$\nabla$

Out of 463 indications, 97 scenarios pertained to screening for colorectal cancer (CRC). Indications related to screening were considered appropriate, uncertain, and inappropriate, in $51 \%$, $20 \%$ and $29 \%$ of scenarios, respectively. Disagreement between panelists occurred in only $7 \%$ of scenarios. Screening was considered mandatory in 33 scenarios ("necessary indications") by the panel. Table 9 shows the definitions used by panelists for the assessment of appropriateness of screening colonoscopy.

- Fig. 1 a shows the overall color-coded panel results as a simplified, clustered dichotomy, of "Not appropriate" ("inappropriate" or "uncertain" grouped together) versus "Appropriate" ("appropriate" and "appropriate and necessary" grouped together). In this simplified view, screening colonoscopy is considered appropriate and possibly necessary in average-risk patients aged over 50 years without prior colonoscopy, patients with slightly or moderately increased risk aged over 40 years, high-risk patients aged over 20 years, patients with a positive FOBT test result, and patients who are found to have adenomas at sigmoidoscopy.

Fig. e1b depicts appropriateness criteria in more detail, with the full range of categories (inappropriate, uncertain, appropriate, 
appropriate and necessary). In average-risk individuals, panelists consider colonoscopy appropriate above 50 years of age. Subsequent screening colonoscopy is then considered appropriate at 10 -year intervals up to the age of 80 . As familial or personal risk of CRC increases, the age at which a first colonoscopy is recommended decreases, to 40 years for slightly and moderately increased risk, and to 20 years of age for high-risk individuals. Similarly, with increasing risk, subsequent surveillance intervals become shorter. A positive FOBT in an asymptomatic individual without personal history of polyps or CRC and without prior colonoscopy is considered an appropriate and even necessary (mandating) indication for performing colonoscopy. While it is deemed appropriate to repeat colonoscopy when FOBT remains positive, even if the first examination is normal, it is even considered necessary to do so after 2 years or more. Colonoscopy is considered appropriate in a patient with low-risk adenomas at sigmoidoscopy, and necessary if sigmoidoscopy reveals high-risk adenomas. Figure e1b also shows for which indications colonoscopy is mandatory (necessary). Failure to carry out the procedure in these situations would represent underuse. For the definition of necessity, refer to the companion article regarding methods in this journal [7].

\section{Conclusions}

\section{$\nabla$}

Colonoscopy is widely recommended as a screening procedure with a high diagnostic and therapeutic yield. In individuals at high risk for CRC, the place of colonoscopy appears to be undisputed. However, debate continues on whether colonoscopy screening should be adopted for average-risk individuals, given the current lack of high-quality evidence based on randomized controlled trials. General screening for CRC in the population has also become a subject of debate in recent years: although it is widely accepted and practiced in many countries, some authors doubt its benefits and therefore advise against widespread screening in the general population.

In spite of the relatively high yield of screening colonoscopy for adenomas and CRC and the results of simulation models, the evidence from small case-controlled studies, and indirect evidence from RCTs and cohort studies on polypectomy, RCTs of FOBT, and case-controlled studies on flexible sigmoidoscopy, does not permit measurement of the real effectiveness of screening colonoscopy for CRC prevention, when considered in terms of CRC and overall mortality reduction. Nevertheless, there is a shift favoring colonoscopy over the other tests in the United States and in some European countries. Compared with the other tests, colonoscopy is more sensitive and allows the removal of polyps, precursors of most CRCs, during the procedure. On the other hand, colonoscopy is associated with complications, and has imperfect sensitivity. Furthermore, the technical quality of colonoscopy may be a matter of concern (e.g., cecal intubation rate, missed lesions, withdrawal time).

The EPAGE II panel considered screening colonoscopy appropriate in average-risk individuals above 50 years, at 40 years in case of slight or moderate risk, and at 20 years in those with high risk for CRC. The appropriate interval for subsequent screening colonoscopy shortens in proportion to the increased risk of CRC. A positive FOBT is always considered an appropriate indication for colonoscopy. If the procedure was not done for necessary (mandating) indications this would represent underuse of colonoscopy.
The results from the EPAGE II panel are available online (http:// www.epage.ch) and may contribute to the optimal use of available resources and to improved patient care regarding colonoscopy.

\section{Acknowledgments \\ $\nabla$}

The authors gratefully acknowledge the selfless commitment and invaluable contribution of the expert panel members, who made this project possible: Lars Agréus (SE), Christoph Beglinger $(\mathrm{CH})$, Peter Bytzer (DK), Michel Delvaux (FR), Volker F. Eckardt (DE), Peter D. Fairclough (UK), François Lacaine (FR), Olivier Le Moine (BE), Vicente Lorenzo Zúñiga Garcia (ES), Giorgio Minoli (IT), Mattijs E. Numans (NL), Daniel Oertli (CH), John O'Malley (UK), Alastair Windsor (UK). The authors warmly thank Susan Giddons for her invaluable assistance in the administration of the expert panel process, as well as in the meticulous preparation of the manuscripts.

This work was supported by a grant from the Loterie Romande (Switzerland).

\section{Competing interests: None}

\section{Appendix: The EPAGE II Study Group}

Lars Agréus, Center for Family and Community Medicine, Karolinska Institutet, Huddinge, Sweden; Christoph Beglinger, Department of Gastroenterology, University of Basle, Basle, Switzerland; Peter Bytzer, Department of Medical Gastroenterology, Køge University Hospital and Copenhagen University, Copenhagen, Denmark; Michel Delvaux, Department of Internal Medicine and Digestive Pathology, CHU de Nancy, Vandoeuvre-les-Nancy, France; Volker F. Eckardt, Gastroenterology Department, Deutsche Klinik für Diagnostik, Wiesbaden, Germany; Peter D. Fairclough, Endoscopy Unit, Barts and The London NHS Trust, London, United Kingdom; François Lacaine, Service de chirurgie digestive, Hôpital Tenon, Paris, France; Olivier Le Moine, Gastroenterology Department, Hôpital Erasme-ULB, Brussels, Belgium; Vicente Lorenzo-Zúñiga, Gastroenterology/Endoscopy, Hospital Universitari Germans Trias I Pujol, Badalona (Barcelona), Spain; Giorgio Minoli, Gastroenterologist, Como, Italy; Mattijs E. Numans, Julius Center for Health Sciences and Primary Care, University Medical Center Utrecht, Utrecht, The Netherlands; Daniel Oertli, Department of Surgery, University of Basle, Basle, Switzerland; John O’Malley, General Practitioner, Moreton, United Kingdom; Alastair Windsor, Department of Surgery, University College London Hospitals, London, United Kingdom. 
Institutions

1 Healthcare Evaluation Unit, Institute of Social and Preventive Medicine (IUMSP), Centre Hospitalier Universitaire Vaudois and University of Lausanne, Lausanne, Switzerland

2 Gastroenterology Department, Deutsche Klinik für Diagnostik, Wiesbaden, Germany

3 Department of Medical Gastroenterology, Køge University Hospital and Copenhagen University, Copenhagen, Denmark

4 Center for Family and Community Medicine, Karolinska Institutet, Huddinge, Sweden

Cerner LifeSciences, Beverly Hills, USA

6 Department of Gastroenterology and Hepatology, Centre Hospitalier Universitaire Vaudois and University of Lausanne, Lausanne, Switzerland

Department of Gastroenterology, University of Basle, Basle, Switzerland

The EPAGE II Study Group*

\section{References}

1 Ferlay J, Autier P, Boniol $M$ et al. Estimates of the cancer incidence and mortality in Europe in 2006. Ann Oncol 2007; 18: 581 - 592

2 Jemal A, Siegel $R$, Ward E et al. Cancer statistics, 2007. CA Cancer J Clin 2007; 57: 43-66

3 Fleshner P, Slater G, Aufses AH jr. Age and sex distribution of patients with colorectal cancer. Dis Colon Rectum 1989; 32: 107-111

4 Sant M, Capocaccia R, Verdecchia A et al. Comparisons of colon-cancer survival among European countries: The Eurocare Study. Int J Cancer 1995; 63: $43-48$

5 Winawer SJ, Fletcher RH, Miller L et al. Colorectal cancer screening clinical guidelines and rationale. Gastroenterology 1997; 112: $594-$ 642

6 Burnand B, Bochud M, Froehlich F et al. 14. Appropriateness of colonoscopy: screening for colorectal cancer in asymptomatic individuals. Endoscopy 1999; 31: 673-683

7 Juillerat P, Peytremann-Bridevaux I, Vader JP et al. Appropriateness of colonoscopy in Europe (EPAGE II) Presentation of methodology, general results, and analysis of complications. Endoscopy 2009; 41: $240-$ 246

8 Rex DK, Cutler CS, Lemmel GT et al. Colonoscopic miss rates of adenomas determined by back-to-back colonoscopies. Gastroenterology 1997; 112: $24-28$

9 Harris JK, Froehlich F, Wietlisbach $V$ et al. Factors associated with the technical performance of colonoscopy: An EPAGE Study. Dig Liver Dis 2007; 39: 678-689

10 Pickhardt PJ, Choi JR, Hwang I et al. Computed tomographic virtual colonoscopy to screen for colorectal neoplasia in asymptomatic adults. N Engl J Med 2003; 349: 2191 - 2200

11 van Gelder RE, Nio CY, Florie J et al. Computed tomographic colonography compared with colonoscopy in patients at increased risk for colorectal cancer. Gastroenterology 2004; 127: 41 - 48

12 Adler A, Roll S, Marowski B et al. Appropriateness of colonoscopy in the era of colorectal cancer screening: a prospective, multicenter study in a private-practice setting (Berlin Colonoscopy Project 1, BECOP 1). Dis Colon Rectum 2007; 50: 1628-1638

13 Byeon JS, Yang SK, Kim TI et al. Colorectal neoplasm in asymptomatic Asians: a prospective multinational multicenter colonoscopy survey. Gastrointest Endosc 2007; 65: 1015 - 1022

14 Eisele R, Vogelsang E, Kraft K et al. Screening for colorectal lesions with high-resolution video colonoscopes in a German male average-risk population at 40 to 59 years of age. Z Gastroenterol 2007; 45: 952 -957

15 Gonvers JJ, Harris JK, Wietlisbach Vet al. A European view of diagnostic yield and appropriateness of colonoscopy. Hepatogastroenterology 2007; 54: 729-735

16 Imperiale TF, Wagner DR, Lin CY et al. Results of screening colonoscopy among persons 40 to 49 years of age. N Engl J Med 2002; 346: 1781 1785

17 Lieberman DA, Weiss DG, Bond JH et al. Use of colonoscopy to screen asymptomatic adults for colorectal cancer. Veterans Affairs Cooperative Study Group 380. N Engl J Med 2000; 343: 162 - 168

18 Morikawa T, Kato J, Yamaji Y et al. A comparison of the immunochemical fecal occult blood test and total colonoscopy in the asymptomatic population. Gastroenterology 2005; 129: $422-428$
19 Regula J, Rupinski M, Kraszewska E et al. Colonoscopy in colorectal-cancer screening for detection of advanced neoplasia. N Engl J Med 2006; 355: $1863-1872$

20 Schoenfeld P, Cash B, Flood A et al. Colonoscopic screening of averagerisk women for colorectal neoplasia. N Engl J Med 2005; 352: 2061 2068

21 Strul H, Kariv R, Leshno M et al. The prevalence rate and anatomic location of colorectal adenoma and cancer detected by colonoscopy in average-risk individuals aged $40-80$ years. Am J Gastroenterol 2006; 101: $255-262$

22 Sung JJ, Chan FK, Leung WK et al. Screening for colorectal cancer in Chinese: comparison of fecal occult blood test, flexible sigmoidoscopy, and colonoscopy. Gastroenterology 2003; 124: 608 - 614

23 Thiis-Evensen E, Hoff GS, Sauar J et al. Flexible sigmoidoscopy or colonoscopy as a screening modality for colorectal adenomas in older age groups? Findings in a cohort of the normal population aged 63-72 years. Gut 1999; 45: 834-839

24 Brenner $H$, Arndt $V$, Sturmer $T$ et al. Long-lasting reduction of risk of colorectal cancer following screening endoscopy. Br J Cancer 2001; 85: $972-976$

25 Cotterchio M, Manno M, Klar N et al. Colorectal screening is associated with reduced colorectal cancer risk: a case-control study within the population-based Ontario Familial Colorectal Cancer Registry. Cancer Causes Control 2005; 16: 865-875

26 Singh H, Turner D, Xue L et al. Risk of developing colorectal cancer following a negative colonoscopy examination: evidence for a 10-year interval between colonoscopies. JAMA 2006; 295: 2366-2373

27 Muller $A D$, Sonnenberg $A$. Prevention of colorectal cancer by flexible endoscopy and polypectomy. A case-control study of 32,702 veterans. Ann Int Med 1995; 123: $904-910$

28 Muller AD, Sonnenberg A. Protection by endoscopy against death from colorectal cancer. A case-control study among veterans. Arch Intern Med 1995; 155: 1741 - 1748

29 Kronborg O, Jorgensen OD, Fenger C, Rasmussen $M$. Randomized study of biennial screening with a faecal occult blood test: results after nine screening rounds. Scand J Gastroenterol 2004; 39: 846-851

30 Mandel JS, Church TR, Ederer F, Bond JH. Colorectal cancer mortality: effectiveness of biennial screening for fecal occult blood. JNCI 1999; 91: 434-437

31 Scholefield JH, Moss S, Sufi F et al. Effect of faecal occult blood screening on mortality from colorectal cancer: results from a randomised controlled trial. Gut 2002; 50: 840 - 844

32 Davila RE, Rajan E, Baron TH et al. ASGE guideline: colorectal cancer screening and surveillance. Gastrointest Endosc 2006; 63: 546-557

33 Imperiale TF, Wagner DR, Lin CY et al. Risk of advanced proximal neoplasms in asymptomatic adults according to the distal colorectal findings. N Engl J Med 2000; 343: 169 - 174

34 Lieberman DA, Weiss DG. One-time screening for colorectal cancer with combined fecal occult-blood testing and examination of the distal colon. N Engl J Med 2001; 345: 555 - 560

35 Bertario L, Russo A, Sala P et al. Predictors of metachronous colorectal neoplasms in sporadic adenoma patients. Int J Cancer 2003; 105: 82 87

36 Citarda F, Tomaselli G, Capocaccia $R$ et al. Efficacy in standard clinical practice of colonoscopic polypectomy in reducing colorectal cancer incidence. Gut 2001; 48: 812-815

37 Jorgensen $O D$, Kronborg $O$, Fenger C, Rasmussen $M$. Influence of longterm colonoscopic surveillance on incidence of colorectal cancer and death from the disease in patients with precursors (adenomas). Acta Oncol (Stockholm, Sweden) 2007; 46: 355-360

38 Thiis-Evensen E, Hoff GS, Sauar J et al. Population-based surveillance by colonoscopy: effect on the incidence of colorectal cancer. Telemark Polyp Study I. Scand J Gastroenterol 1999; 34: 414-420

39 Winawer SJ, Zauber AG, Ho MN et al. Prevention of colorectal cancer by colonoscopic polypectomy (The National Polyp Study Workgroup). N Engl J Med 1993; 329: 1977-1981

40 Frazier AL, Colditz GA, Fuchs CS, Kuntz KM. Cost-effectiveness of screening for colorectal cancer in the general population. JAMA 2000; 284: $1954-1961$

41 Sonnenberg A, Delco $F$. Cost-effectiveness of a single colonoscopy in screening for colorectal cancer. Arch Intern Med 2002; 162: 163-168

42 Vijan S, Hwang EW, Hofer TP, Hayward RA. Which colon cancer screening test? A comparison of costs, effectiveness, and compliance. Am J Med 2001; 111: 593-601

\footnotetext{
* See Appendix: The EPAGE II Study Group
} 
43 Australian Cancer Network Colorectal Cancer Guidelines Revision Committee. Guidelines for the prevention, early detection and management of colorectal cancer. Sydney: The Cancer Council Australia and Australian Cancer Network, 2005

44 Coombs A, Jones-McLean E, Le Petit C et al. Technical report for the National Committee on Colorectal Cancer Screening; 2002. Available at: www.phac-aspc.gc.ca/publicat/ncccs-cndcc/ackn-eng.php

45 Kaiser Permanente Care Management Institute. Colorectal cancer screening clinical practice guideline. Oakland, California: Kaiser Permanente Care Management Institute, 2006

46 Levin B, Burt RW, Drelichman E et al. Colorectal cancer screening. National Comprehensive Cancer Network, 2007

47 McLeod RS with the Canadian Task Force on Preventive Health Care. Screening strategies for colorectal cancer. Systematic review and recommendations. Canadian Task Force on Preventive Health Care, 2001

48 Rex DK, Johnson DA, Lieberman DA et al. Colorectal cancer prevention 2000: screening recommendations of the American College of Gastroenterology. American College of Gastroenterology. Am J Gastroenterol 2000; 95: 868 - 877

49 Smith RA, Cokkinides V, Eyre HJ. American Cancer Society guidelines for the early detection of cancer, 2006. CA Cancer J Clin 2006; 56: 11 - 25

50 US Preventive Services Task Force. Screening for colorectal cancer: recommendation and rationale. Ann Intern Med 2002; 137: 129-131

51 Winawer S, Fletcher R, Rex D et al. Colorectal cancer screening and surveillance: clinical guidelines and rationale - update based on new evidence. Gastroenterology 2003; 124: 544- 560

52 Levin B, Lieberman DA, McFarland B et al. Screening and surveillance for the early detection of colorectal cancer and adenomatous polyps, 2008: a joint guideline from the American Cancer Society, the US Multi-Society Task Force on Colorectal Cancer, and the American College of Radiology. Gastroenterology 2008; 134: 1570 - 1595

53 Lieberman DA, Weiss DG, Harford WV et al. Five-year colon surveillance after screening colonoscopy. Gastroenterology 2007; 133: 1077-1085

54 Rex DK, Cummings OW, Helper DJ et al. 5-year incidence of adenomas after negative colonoscopy in asymptomatic average-risk persons. Gastroenterology 1996; 111: 1178-1181

55 Allison JE, Sakoda LC, Levin TR et al. Screening for colorectal neoplasms with new fecal occult blood tests: update on performance characteristics. JNCI 2007; 99: $1462-1470$

56 Allison JE, Tekawa IS, Ransom LJ, Adrain AL. A comparison of fecal occult blood tests for colorectal cancer screening. N Engl J Med 1996; 334: $155-159$

57 Greenberg PD, Bertario L, Gnauck $R$ et al. A prospective multicenter evaluation of new fecal occult blood tests in patients undergoing colonoscopy. Am J Gastroenterol 2000; 95: 1331 -1338

58 Brevinge $H$, Lindholm E, Buntzen S, Kewenter J. Screening for colorectal neoplasia with faecal occult blood testing compared with flexible sigmoidoscopy directly in a 55-56 years old population. Int J Colorect Dis 1997; 12: 291 - 295

59 Hardcastle JD, Chamberlain JO, Robinson $\mathrm{MH}$ et al. Randomised controlled trial of faecal-occult-blood screening for colorectal cancer. Lancet $1996 ; 348: 1472-1477$

60 Jorgensen $O D$, Kronborg $O$, Fenger $C$. A randomised study of screening for colorectal cancer using faecal occult blood testing: results after 13 years and seven biennial screening rounds. Gut 2002; 50: 29-32

61 Kewenter J, Brevinge H, Engaras B et al. Follow-up after screening for colorectal neoplasms with fecal occult blood testing in a controlled trial. Dis Colon Rectum 1994; 37: 115-119

62 Kronborg O, Fenger C, Olsen J et al. Randomised study of screening for colorectal cancer with faecal occult blood test. Lancet 1996; 348: 1467 - 1471

63 Mandel JS, Bond JH, Church TR et al. Reducing mortality from colorectal cancer by screening for fecal occult blood. Minnesota Colon Cancer Control Study. N Engl J Med 1993; 328: 1365-1371

64 Mandel JS, Church TR, Bond JH et al. The effect of fecal occult-blood screening on the incidence of colorectal cancer. N Engl J Med 2000; 343: $1603-1607$

65 Hewitson P, Glasziou P, Irwig L et al. Screening for colorectal cancer using the faecal occult blood test, Hemoccult. Cochrane Database Syst Rev 2007; CD001216:

66 Lang CA, Ransohoff DF. Fecal occult blood screening for colorectal cancer. is mortality reduced by chance selection for screening colonoscopy? Jama 1994; 271: $1011-1013$
67 Solomon MJ, McLeod RS. Periodic health examination, 1994 update: 2. Screening strategies for colorectal cancer. Canadian Task Force on the Periodic Health Examination. Can Med Assoc J 1994; 150: 1961 - 1970

68 Foutch PG, Mai H, Pardy K et al. Flexible sigmoidoscopy may be ineffective for secondary prevention of colorectal cancer in asymptomatic, average-risk men. Dig Dis Sci 1991; 36: 924-928

69 Lieberman DA, Smith FW. Screening for colon malignancy with colonoscopy. Am J Gastroenterol 1991; 86: 946 - 951

70 Anderson JC, Alpern Z, Messina CR et al. Predictors of proximal neoplasia in patients without distal adenomatous pathology. Am J Gastroenterol 2004; 99: $472-477$

71 Hoff G, Sauar J, Vatn MH et al. Polypectomy of adenomas in the prevention of colorectal cancer: 10 years' follow-up of the Telemark Polyp Study I. A prospective, controlled population study. Scand J Gastroenterol 1996; 31: 1006 - 1010

72 Thiis-Evensen E, Hoff GS, Sauar J et al. The effect of attending a flexible sigmoidoscopic screening program on the prevalence of colorectal adenomas at 13-year follow-up. Am J Gastroenterol 2001; 96: 1901 1907

73 UK Flexible Simoidoscopy Screening Trial Investigators. Single flexible sigmoidoscopy screening to prevent colorectal cancer: baseline findings of a UK multicentre randomised trial. Lancet 2002; 359: 1291 1300

74 Atkin WS, Edwards R, Wardle J et al. Design of a multicentre randomised trial to evaluate flexible sigmoidoscopy in colorectal cancer screening. J Med Screen 2001; 8: 137 - 144

75 Bretthauer M, Gondal G, Larsen K et al. Design, organization and management of a controlled population screening study for detection of colorectal neoplasia: attendance rates in the NORCCAP study (Norwegian Colorectal Cancer Prevention). Scand J Gastroenterol 2002; 37 : $568-573$

76 Gondal G, Grotmol T, Hofstad B et al. The Norwegian Colorectal Cancer Prevention (NORCCAP) screening study: baseline findings and implementations for clinical work-up in age groups 50-64 years. Scand Gastroenterol 2003; 38: 635-642

77 Segnan N, Senore C, Andreoni B et al. Randomized trial of different screening strategies for colorectal cancer: patient response and detection rates. JNCI 2005; 97: $347-357$

78 Segnan N, Senore C, Andreoni B et al. Baseline findings of the Italian multicenter randomized controlled trial of "once-only sigmoidoscopy" - SCORE. JNCI 2002; 94: 1763-1772

79 Segnan N, Senore C, Andreoni B et al. Comparing attendance and detection rate of colonoscopy with sigmoidoscopy and FIT for colorectal cancer screening. Gastroenterology 2007; 132: 2304-2312

80 Weissfeld JL, Schoen RE, Pinsky PF et al. Flexible sigmoidoscopy in the PLCO cancer screening trial: results from the baseline screening examination of a randomized trial. JNCI 2005; 97: 989-997

81 Newcomb PA, Storer BE, Morimoto LM et al. Long-term efficacy of sigmoidoscopy in the reduction of colorectal cancer incidence. JNCI 2003; 95: $622-625$

82 Slattery ML, Edwards SL, Ma KN, Friedman GD. Colon cancer screening, lifestyle, and risk of colon cancer. Cancer Causes Control 2000; 11: $555-563$

83 Mulhall BP, Veerappan GR, Jackson JL. Meta-analysis: computed tomographic colonography. Ann Int Med 2005; 142: 635-650

84 Imperiale TF, Ransohoff DF, Itzkowitz SH et al. Fecal DNA versus fecal occult blood for colorectal-cancer screening in an average-risk population. N Engl J Med 2004; 351: 2704-2714

85 Butterworth AS, Higgins JPT, Pharoah P. Relative and absolute risk of colorectal cancer for individuals with a family history: a meta-analysis. Eur J Cancer 2006; 42: 216-227

86 Johns LE, Houlston RS. A systematic review and meta-analysis of familial colorectal cancer risk. Am J Gastroenterol 2001; 96: 2992 - 3003

87 Cottet V, Pariente A, Nalet B et al. Colonoscopic screening of first-degree relatives of patients with large adenomas: increased risk of colorectal tumors. Gastroenterology 2007; 133: 1086-1092

88 Guillem JG, Forde KA, Treat MR et al. Colonoscopic screening for neoplasms in asymptomatic first- degree relatives of colon cancer patients. A controlled, prospective study. Dis Colon Rectum 1992; 35 $523-529$

89 Rex DK. Colonoscopy: a review of its yield for cancers and adenomas by indication. Am J Gastroenterol 1995; 90: 353 - 365

90 Sauar J, Hausken T, Hoff G et al. Colonoscopic screening examination of relatives of patients with colorectal cancer. I. A comparison with an en- 
doscopically screened normal population. Scand J Gastroenterol 1992; 27: $661-666$

91 Dowling DJ, St John DJ, Macrae FA, Hopper JL. Yield from colonoscopic screening in people with a strong family history of common colorectal cancer. J Gastroenterol Hepatol 2000; 15: 939-944

92 Niv Y, Dickman R, Figer A et al. Case-control study of screening colonoscopy in relatives of patients with colorectal cancer. Am J Gastroenterol 2003; 98: 486-489

93 French National Agency for Accreditation and Evaluation in Healthcare. Clinical practice guidelines: indications for lower gastrointestinal endoscopy (excluding population screening). 2004. Available at: http:// www.has-sante.fr/portail/upload/docs/application/pdf/Endoscopy_ guidelines.pdf

94 New Zealand Guidelines Group. Surveillance and management of groups at increased risk of colorectal cancer. Wellington, New Zealand:New Zealand Guidelines Group (NZGG); 2004. Available at: www.nzgg.org.nz/guidelines/0048/040624_FINAL_Full_for_Web_ Colorectal_Guideline1.pdf

95 Cairns S, Scholefield JH. Guidelines for colorectal cancer screening in high risk groups. Gut 2002; 51 Suppl 5: V1 - V2

96 Scottish Intercollegiate Guidelines Network. Management of colorectal cancer. A national clinical guideline. Edinburgh (Scotland): Scottish Intercollegiate Guidelines Network (SIGN), 2003

97 Vasen HF, Mecklin JP, Watson P et al. Surveillance in hereditary nonpolyposis colorectal cancer: an international cooperative study of $165 \mathrm{fa}-$ milies. The International Collaborative Group on HNPCC. Dis Colon Rectum 1993; 36: 1-4

98 Vasen HF, Moslein G, Alonso A et al. Guidelines for the clinical management of Lynch syndrome (hereditary non-polyposis cancer). J Med Genet 2007; 44: 353-362

99 Lynch HT, Smyrk T, Lynch J et al. Update on the differential diagnosis, surveillance and management of hereditary non-polyposis colorectal cancer. Eur J Cancer 1995; 31A : 1039-1046
100 Jarvinen HJ, Aarnio M, Mustonen $\mathrm{H}$ et al. Controlled 15-year trial on screening for colorectal cancer in families with hereditary nonpolyposis colorectal cancer. Gastroenterology 2000; 118: 829-834

101 Jarvinen HJ, Mecklin JP, Sistonen P. Screening reduces colorectal cancer rate in families with hereditary nonpolyposis colorectal cancer. Gastroenterology 1995; 108: 1405-1411

102 Heiskanen I, Luostarinen T, Jârvinen HJ. Impact of screening examinations on survival in familial adenomatous polyposis. Scand J Gastroenterol 2000; 35: 1284-1287

The following figure and tables are available online: www.thieme-connect.com/media/endoscopy/200903/supmat/ endo844.pdf

Fig. e1b Appropriateness ratings of clinical indications for performing colonoscopy in patients for colorectal cancer (CRC) screening: (full decision tree). HNPCC, hereditary nonpolyposis colorectal cancer; FAP, familial adenomatous polyposis; FOBT, fecal occult blood test. Table e1 Diagnostic yield of colonoscopy screening for colorectal cancer (CRC).

Table e2 Case-controlled and cohort studies of colonoscopy screening for colorectal cancer (CRC).

Table e3 Guidelines for colorectal cancer (CRC) screening.

Table e4 Randomized controlled trials of fecal occult blood test (FOBT) screening versus no screening for colorectal cancer (CRC).

Table e5 Case-controlled and cohort studies involving sigmoidoscopy screening for colorectal cancer (CRC).

Table e6 Guidelines for colorectal cancer (CRC) screening in individuals with a family history of CRC or adenomatous polyps.

Table e7 Guidelines for colorectal cancer (CRC) screening in individuals with a family history of hereditary nonpolyposis colorectal cancer (HNPCC).

Table e8 Guidelines for colorectal cancer (CRC) screening in individuals with a family history of familial adenomatous polyposis (FAP). 